\title{
Implementing Precision Approaches Supported by Satellite-Based Augmentation Systems in the Austrian Alps
}

\author{
Carlos Gonzaga-López* and Florian Michael Buchmann* \\ Austro Control, GmbH, 1220 Vienna, Austria \\ and \\ Thomas Dautermann $\ddagger$ and Thomas Ludwig $\ddagger$ \\ DLR, German Aerospace Center, 38108 Brunswick, Germany
}

\begin{abstract}
https://doi.org/10.2514/1.D0155
Aerodromes located in mountainous areas are seldom served by approaches with three-dimensional guidance based on instrument landing systems due to the lack of flexibility to define glide paths free of obstacles. But, threedimensional approaches are always preferred due to their effectiveness against controlled flight into terrain. Free access to three-dimensional angular approaches is possible today without special authorization and ground infrastructure. Some airports in mountainous areas of the United States, Canada, and Europe already benefit from them due to the latest advances in satellite-based augmentation techniques. The majority of these procedures have not been developed as category-one precision approaches, even though the latest operational service level foresees it. Reported here are the signal assessment and procedure design carried out to enable the first category-one precision approach supported by satellite-based augmentation system at an Austrian airport surrounded by one of the most challenging terrains worldwide. The design and implementation of such a procedure in mountainous terrain is feasible after a thorough signal quality assessment. It can be placed where a classical instrument landing-system-based approach procedure does not work and provides precision guidance for aircraft in instrument meteorological conditions. This in turn enables a higher runway throughput and reduces cost for the users. When the controlling obstacle is located outside of the precision segment, special attention should be put on the availability requirements.
\end{abstract}

\section{Introduction}

A ERODROMES in demanding mountainous environments are usually served by two-dimensional (2-D) approach procedures without vertical guidance to achieve lower minima by establishing stepdown descent profiles. However, the absence of vertical guidance increases significantly the likelihood of controlled flight into terrain (CFIT) due to loss of situational awareness and high cockpit workload during approach and landing in instrument meteorological conditions when any outside references can only be visually acquired shortly before landing. CFIT is a type of aircraft accident in which an airworthy aircraft with full pilot control is unintentionally flown into the ground, into a mountain, or into an obstacle. Usually, the flight crew is oblivious of the imminent danger. The International Civil Aviation Organization's (ICAO's) Assembly Resolution A37-11 urges member states to implement instrument approach procedures (IAPs) with vertical guidance, wherever possible, as an effective mitigation against CFIT. An IAP is a repeatable and charted method to conduct an approach for landing at an airport. It safely guides the aircraft from arrival altitude to a point from which the landing can be performed.

The recent developments in the field of Global Navigation Satellite Systems (GNSSs) and its augmentations have opened up a new spectrum of possibilities in aviation. Concretely, the satellite-based augmentation system (SBAS) [1] now enables three-dimensional (3-D) instrument landing system (ILS)-like approaches, also known as localizer performance with vertical guidance (LPV). Both provide angular deviations from the centerline and glide path to the pilot, but the ILS does so by means of ground-based radio transmitters, whereas LPV is computed from GNSS position data. LPV approaches

Received 18 November 2018; revision received 17 April 2020; accepted for publication 17 May 2020; published online Open Access 11 June 2020. Copyright $(\mathcal{C} 2020$ by the authors. Published by the American Institute of Aeronautics and Astronautics, Inc., with permission. All requests for copying and permission to reprint should be submitted to CCC at www.copyright.com; employ the eISSN 2380-9450 to initiate your request. See also AIAA Rights and Permissions www.aiaa.org/randp.

*Air Traffic Management Department, IFP Office, Wagramer Straße 19.

${ }^{\dagger}$ Ph.D., Institute of Flight Guidance, Department of Pilot Assistance, Lilienthalplatz 7, Braunschweig; Thomas.Dautermann@dlr.de. have proven to be a cost-efficient solution to overcome airspace limitations and reduce noise impact [2]. Legacy design criteria and available levels of service, known as the approach procedure with vertical guidance (APV), have supported LPV operations down to $250 \mathrm{ft}$ above runway threshold for many years. With the improvement of the signal performance, new operational service levels and design criteria have been defined to support LPV operations down to $200 \mathrm{ft}$, qualifying these types of procedures as precision approaches for the first time. This is called LPV200 or LPV category-one (CAT-I). As of January of 2019 there are around 4000 LPV operational approaches in the United States of America (USA), 400 in Canada, and around 500 in Europe. India and Japan are expected to publish their first LPV approaches in the near future. However, the implementation of precision approaches in complex mountainous environments is still marginal. High aerodrome operating minima in terms of decision height $(\mathrm{DH})$ and the blockage of satellite signals by terrain (also known as terrain masking) are the most common limiting factors $[\underline{3}, \underline{4}] . \mathrm{DH}$ is the minimum height above ground at which the pilot must have established visual reference to the landing runway. If this is not the case, he or she must follow a predetermined missed approach procedure. The LPV approaches to the Astronaut Kent Rominger Airport (ICAO code KRCV) from the east and to Mc Elroy Airfield (ICAO code K20V) from the north in the state of Colorado constitute good examples of approaches in challenging terrain with landing minima well above $250 \mathrm{ft}$ [5]. In the USA, LPVs are designed as category-one precision approaches only if the corresponding landing minima can be below $250 \mathrm{ft}$ as, for example, the approach to Jackson Hole (ICAO code KJAC) from the north in the state of Wyoming [5]. This is not always the case in Europe, where a mixture of legacy APVs and new CAT-I LPVs can be found serving runways where prevailing terrain precludes CAT-I landing minima below $250 \mathrm{ft}$. For example, the LPV approaches to Sogndal (ICAO code ENSG) (Norway) from the east [6] and to Annecy (ICAO code LFLP) (France) from the south [7] were designed as CAT-I precision approaches, even though the resulting DH lies well above $250 \mathrm{ft}$, thus discarding any possibility of CAT-I operations based on the SBAS. On the other hand, LPV approaches in similar environments, such as those to the regional airport of Bern-Belp (ICAO code LSZB) (Switzerland) []ㅡ, were designed as APVs and not as precision approaches. 
The fact that LPV approaches are independent of ground infrastructure is of particular relevance for small general and business aviation aerodromes where the costs of instrument landing aids do not fulfill the business case or where the topography impedes the optimal placement of such. The Austrian airport of Innsbruck, under ICAO code LOWI, represents a good example of this limitation. This airport lies in a valley flanked by high and steep mountains (see Fig. 1), which can pose a great challenge to pilots and air traffic controllers in combination with adverse weather. Accessibility to Innsbruck airport is key to the economic development of the region, especially during the winter season. For that reason, Innsbruck is a breeding ground for some of the most innovative flight procedures worldwide.

The most advanced 3-D approaches currently implemented in Innsbruck are based on the navigation specification of required navigation performance (RNP)/authorization required (AR), referred to as RNP-AR, and are flown by most airliners with special authorization. A navigation specification can be seen as a set of aircraft and crew requirements that need to be met for a specific phase of flight. The navigation specification also defines the navigational tolerances that are to be used to create the containment areas and assess obstructions according to the specific design criteria. A detailed list of the available navigation specification to date can be found in Ref. [9]. RNP-AR capabilities are traditionally out of scope for the general aviation community due to the increased costs associated with more demanding training and airworthiness certification requirements. No 3-D approach procedure based on standard RNP navigation specification (without special authorization required), conventional ILS, or a combination of both could be implemented until now in Innsbruck due to topographic constraints. As a consequence, most general aviation inbound flights to runway 26 (standard approach configuration) still rely on a 2-D offset localizer/distance measuring equipment (LOC/DME) approach. In a LOC/DME approach procedure, the lateral guidance is provided by a very high-frequency-based localizer directional aid [10] and distance information is provided by ultrahigh frequency distance measuring equipment (DME). In this nonprecision approach, the vertical path is managed by the pilot through altitude restrictions at stepdown fixes. Despite the existence of a steep advisory glide slope at a nonstandard vertical path angle (VPA) in Innsbruck, the publication of standard 3-D approaches can contribute to lowering the risk of CFIT by enabling better aircraft energy management during the approach with less pilot workload. The safety benefits are even more evident if the approach guidance system provides the user with angular sensitivity and geometrical vertical guidance. This type of vertical guidance is not subject to barometric altimetry errors such as temperature variations and Bernoulli effects, which are very common in mountainous areas. Moreover, GNSSguided approaches eliminate critical areas in the final approach due to reflection of the glide slope and/or localizer beams.

In this paper, we describe the implementation process carried out to make possible the first 3-D approach with angular sensibility at the alpine airport of Innsbruck, based on SBAS and with no special authorization requirement.

\section{Signal Analysis}

We considered European Geostationary Navigation Overlay Service (EGNOS) as the most appropriate technological means to date in order to provide approach navigation service to the general and business aviation community in Innsbruck. EGNOS is a SBAS, i.e., an enhanced differential Global Positioning System (GPS) that provides signal corrections plus signal quality parameters to users. The user can then augment its measurements to compute a more precise position. SBAS provides means for high-quality approaches that do not depend on ground-based navigational aids and do not require any special approval. Since 2015, EGNOS offers the LPV200 service level on a free-of-charge basis in an extensive area across Europe [11]. This service level supports 3-D approach operations of type B down to $200 \mathrm{ft}$ above runway threshold elevation [12], whereas the legacy LPV service level does down to $250 \mathrm{ft}$. The LPV200 service also enables the application of ICAO CAT-I design criteria with less restrictive obstacle assessment surfaces (OASs) [13]. Further details on Global Navigation Satellite System signal-in-space requirements for SBAS CAT-I design criteria can be found in Ref. [14]. Before undertaking the design phase of the flight procedure, it is of paramount importance to ensure the availability of the required signal in the area of interest. Given the complex topography of the alpine area of Innsbruck and its possible effects on the augmented navigational signal, we decided to use a combined approach based on both simulations and on-site measurements.

\section{A. Terrain Masking}

To predict EGNOS performance in Innsbruck, we used a digital terrain model of the mountainous topography surrounding the airport with a spatial resolution of $50 \mathrm{~m}$. We chose seven characteristic points on the existing runway (RWY) 26 localizer (LOC) approach at which we calculated satellite elevation masks due to the terrain with a resolution of $5 \mathrm{deg}$ in azimuth (see Fig. 1). Obstructions due to terrain become more prominent the lower on the approach the aircraft is located. Figure 2 shows that, at the lowest point on the existing LOC/DME approach (at $3.5 \mathrm{n}$ miles of DME distance), both EGNOS satellites are still visible to the user. The position of the EGNOS broadcast satellite Pseudo Random Noise (PRN)120 is marked in red, whereas the PRN136 is marked in black. The terrain elevation mask can reach up to $16 \mathrm{deg}$ at a direction of $345 \mathrm{deg}$ from the airport. However, in the north, there are few satellites visible due to the Global Positioning System orbital geometry.

\section{B. Protection Level Prediction}

To assess EGNOS performance for the LPV200 service level in Innsbruck, we need to calculate a prediction of integrity data in the form of protection levels as calculated by a receiver in real time. Protection levels correspond to the ad hoc estimate of the position uncertainty with a probability of one minus the integrity risk. In other words, if the integrity risk is $2 \times 10^{-7}$, then the user is $99.99998 \%$ certain that the estimated position is within the cylinder defined by radius horizontal protection level (HPL) and height vertical protection

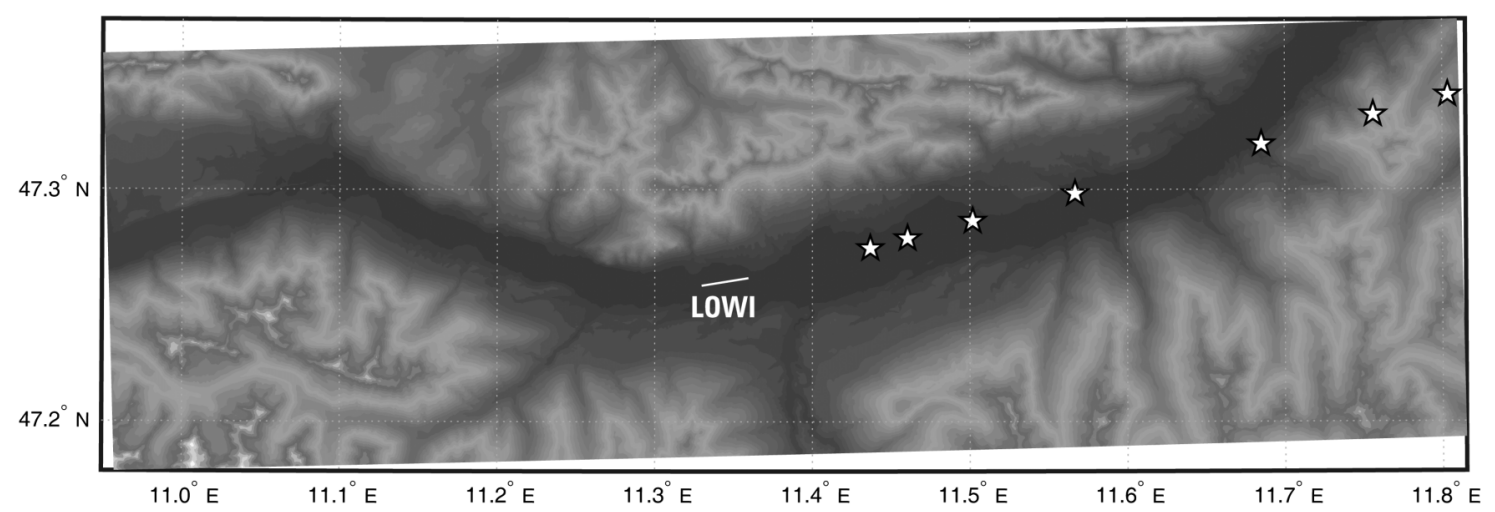

Fig. 1 Terrain elevation around Innsbruck airport (ICAO identifier LOWI) and characteristic points. Light tones represent the highest elevations. 


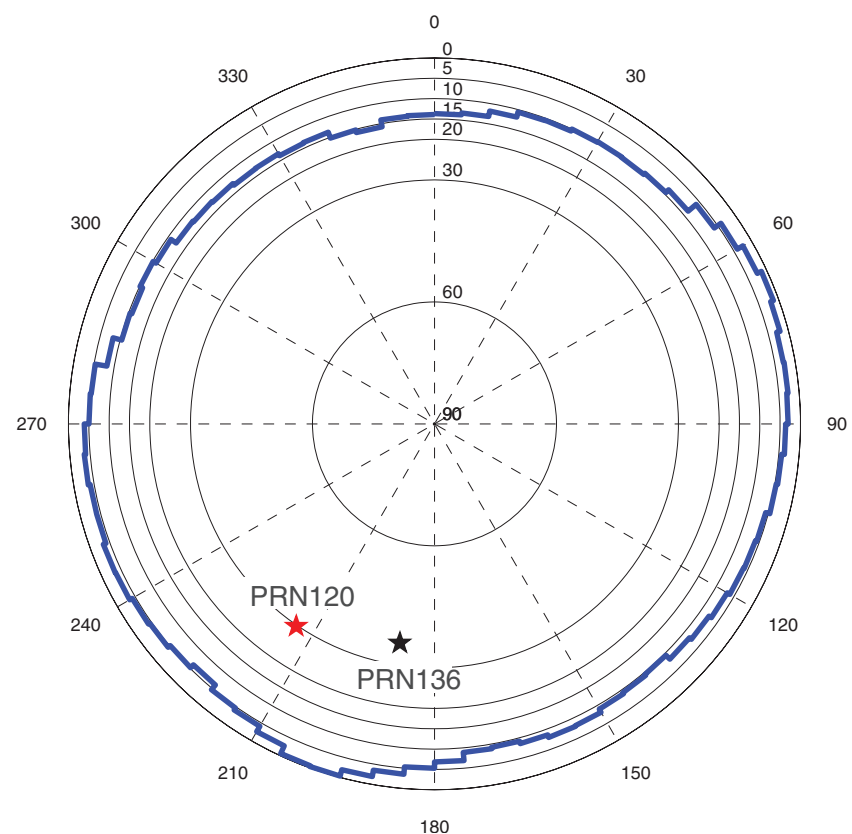

Fig. 2 Terrain elevation mask (vertical axis in degrees) at 3.5 DME and $1410 \mathrm{ft}$ Above Ground Level (AGL) on LOC approach to Innsbruck RWY 26. Azimuth axis in degrees (0 represents true north). Inside the blue line, satellites are visible to the GNSS receiver. Outside the blue line, terrain obscures and blocks signal reception.

level (VPL). Details on the SBAS message and the calculation of augmented user position and integrity data can be found, for example, in Ref. [15]. The main model parameters needed for the calculation of the protection levels are the satellite geometry, the user differential range error index (UDREI), and the grid ionosphere vertical error index (GIVEI). UDREIs are 4 bit integer data that are broadcast by the SBAS satellites and used to indicate the accuracy of combined fast and long-term error corrections. The SBAS system assigns an integer from 0 through 15 to each GNSS constellation satellite that is monitored. By means of a lookup table in Ref. [15], a variance is assigned and used in the computation of position and protection levels. Similarly, the SBAS broadcasts information about the current state of the ionosphere. These data consist of the vertical ionosphere signal delay and the GIVEI. Again, the GIVEI are 4 bit integer values from 0 to 15 describing the variance of the ionosphere delay estimate at each grid point. To compute a meaningful prediction of the protection levels, and thus EGNOS performance, we need to make qualified assumptions on those quantities. They are also the main input parameters of Stanford University's MATLAB Algorithm Availability Simulation Tool (MAAST) [16]. MAAST provides proven program code for simulation of the GPS constellation based on ephemeris data and user location as well as performance tools to analyze navigation integrity, availability, continuity, and accuracy. We calculated predicted approach protection levels using a current almanac (basic set of parameters describing a satellite orbit [17]) from GPS week $841(+1024)$ and the Stanford MAAST Toolkit. Since the standard MAAST does not foresee to use different UDREIs and GIVEIs per satellite, we modified the open software to include this functionality. Details on MAAST can be found in Ref. [16]. To obtain a realistic value for the GIVEI and UDREI, we ran a statistical analysis over all GIVEI data for the EGNOS in band 4 and band 5 located over central Europe. Bands 4 and 5 are sufficient because they cover most of the central European landmass. An overview of the grid point locations and bands can be found in RTCA Standard DO-229D [15]. The EGNOS message data were obtained from the EGNOS

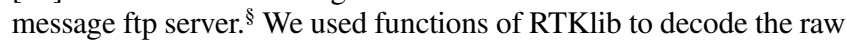
messages and extract the relevant GIVEI data. Details on the RTKlib

\footnotetext{
${ }^{\S}$ Data available online at ftp://ems.estec.esa.int/pub/ [retrieved 27 October 2016].
}

functionality can be found in Ref. [18]. We also performed a statistical analysis on the UDREI per PR $\bar{N}$. From the statistical data, we calculated the mean of the UDREI for 2015 and rounded up to the nearest integer value. Using MAAST and the average GIVEI and UDREI from 2015, as well as the satellite elevation masks based on terrain, we computed $24 \mathrm{~h}$ predictions of the protection levels at each one of the previously identified points. The results are shown in Fig. 3. This figure shows the VPL at different DME distances $\mathrm{n}$ miles on the current LOC/DME approach and the number of satellites used. As the altitude on the approach increases, the terrain obstruction diminishes and more satellites become visible. This, in turn, decreases the protection level. As expected, the lowest selected point at $3.5 \mathrm{n}$ miles gives the least satellite visibility and the largest protection level.

We can see that the VPL at the 4.5-n-mile DME position at times of 5.5 and $12 \mathrm{~h}$ has a higher value than the one at the 3.5-n-mile DME. At first sight, this appears contradictory since the point is located higher on the approach path. However, the Wipp Valley shifts its position relative to the user, causing a different satellite masking. The Wipp Valley is located to the south of Innsbruck and leads to the Brenner Pass, which is the main transit route from the Austrian Alps to Italy. Relative to the approach to Innsbruck airport, it provides an area of unobstructed view of the sky in the south. Therefore, from this location, signals from GPS satellites can be received. From Fig. 1, we can see that, relative to the points at which the EGNOS performance is being evaluated, this patch of clear view to the sky changes position, and thus masks different portions of the sky at low elevation. If a satellite is being removed from the navigation solution, the protection level increases.

SBAS CAT-I approaches supported by EGNOS LPV200 service require a vertical alert limit (VAL) of $35 \mathrm{~m}$ and a horizontal alert limit (HAL) of $40 \mathrm{~m}$ [11]. Given these requirements and the outcome of the MAAST simulation, we predict $100 \%$ availability in Innsbruck in the normal case; i.e., no GPS satellite is out of service.

Furthermore, we simulated satellite failure of various satellites during the day. The satellites were chosen as the ones giving the highest increase in dilution of precision when removed successively. The results, displayed in Fig. 4, show conformance with the required availability (99\% as per Ref. [14]) based on the parameters of the prediction. Even if two or more critical satellites failed, leading to very short violations of the required VAL at very specific moments during the day, the impact on the service operation would be far from relevant. This is due to the probability of an unscheduled single satellite failure interruption. According to Ref. [19], it is less than 0.0002 , making a dual satellite failure highly unlikely at $4 \times 10^{-8}$.
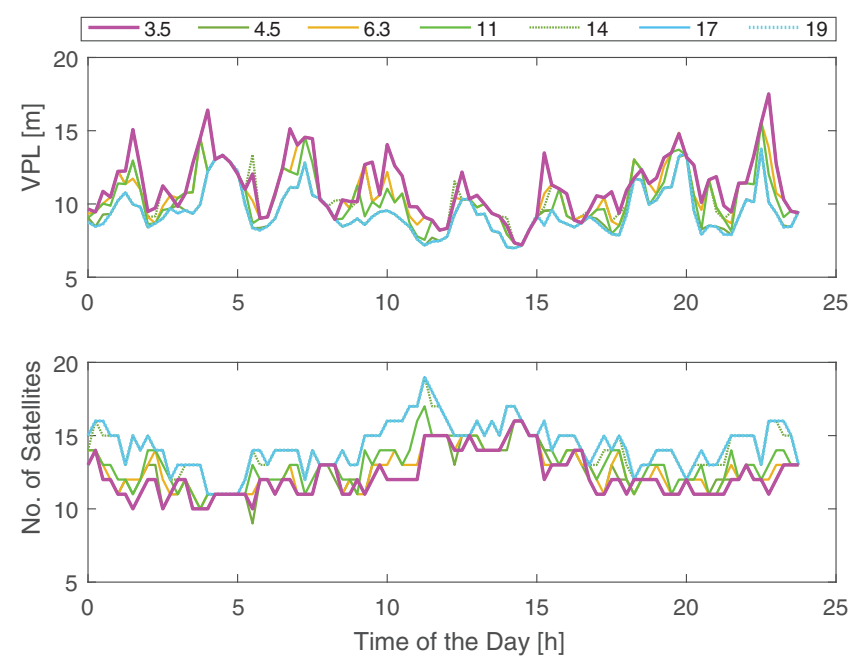

Fig. 3 Vertical protection levels at different DME distances (nautical miles) on the current LOC/DME approach (top) and number of satellites used (bottom). The alert limit in the top graph is $35 \mathrm{~m}$ and not shown since it would obscure data variations. 


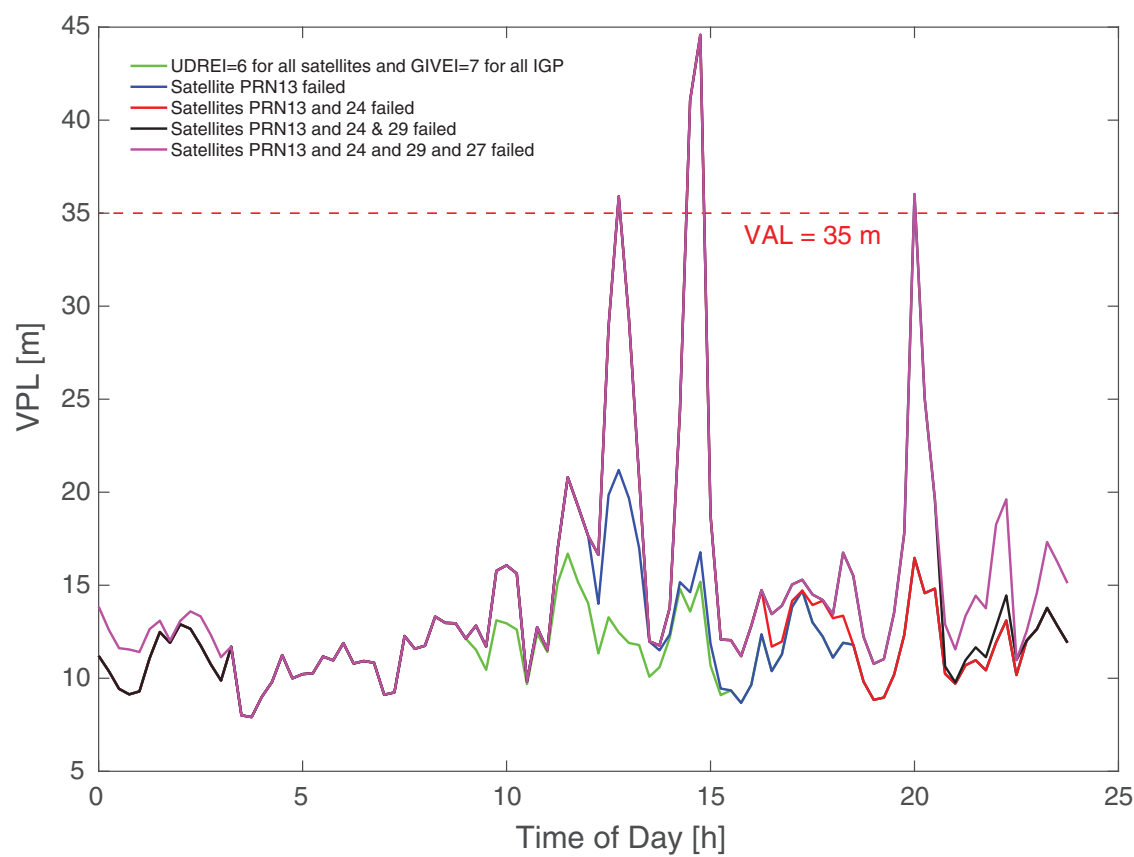

Fig. 4 Vertical protection levels at the airport assuming several satellite failures throughout the day.

\section{Availability Measurements}

To confirm the results of the simulations with MAAST, we performed a $24 \mathrm{~h}$ error measurement campaign at Innsbruck airport from 1 March 2017 at $1200 \mathrm{hrs}$ until 2 March 2017 at $1300 \mathrm{hrs}$ local time, as in the submitted manuscript. One extra hour was added due to more time available for recording data. We used the permanent GNSS L1/L2 antenna mounted on the localizer shelter that usually provides reference data for the calibration of the localizer signal. To have comparable results, we added this position as point D0.0 to the MAAST Simulation and reran the prediction for this additional point again. During a measurement campaign, main parameters can be different from the ones used in the simulation. The most important one is the satellite almanac used for the simulation and the orbital parameters of the actual constellation during the measurements. Figure 5 shows the differences between varying the input parameters of the UDREI, GIVEI, and age of the almanac of the MAAST, bringing the prediction closer to reality. The largest impact on the calculation of the protection levels is provided by the almanac used to simulate satellite orbits. Using the averaged UDREI or averaged GIVEI only influences the computation of the protection levels at an average of $7.7 \%$ as the protection levels map the residual pseudorange error into the position domain. The mapping function is computed from the satellite orbits, whereas the residual pseudorange error is provided by the UDREI and GIVEI. Since, on a regular day (no solar flares, no satellite clock runaways, etc.), the transmitted error indices are relatively close to their mean value, the use of the actual value does not influence the protection level much. Using an older almanac with a significant change in orbital parameters has a great influence on the mapping function and can lead to a change in protection levels to the point that the correlation between the simulation results is close to zero. Figure 6 shows the protection level as measured on 1 March 2017 at the localizer shelter of Innsbruck

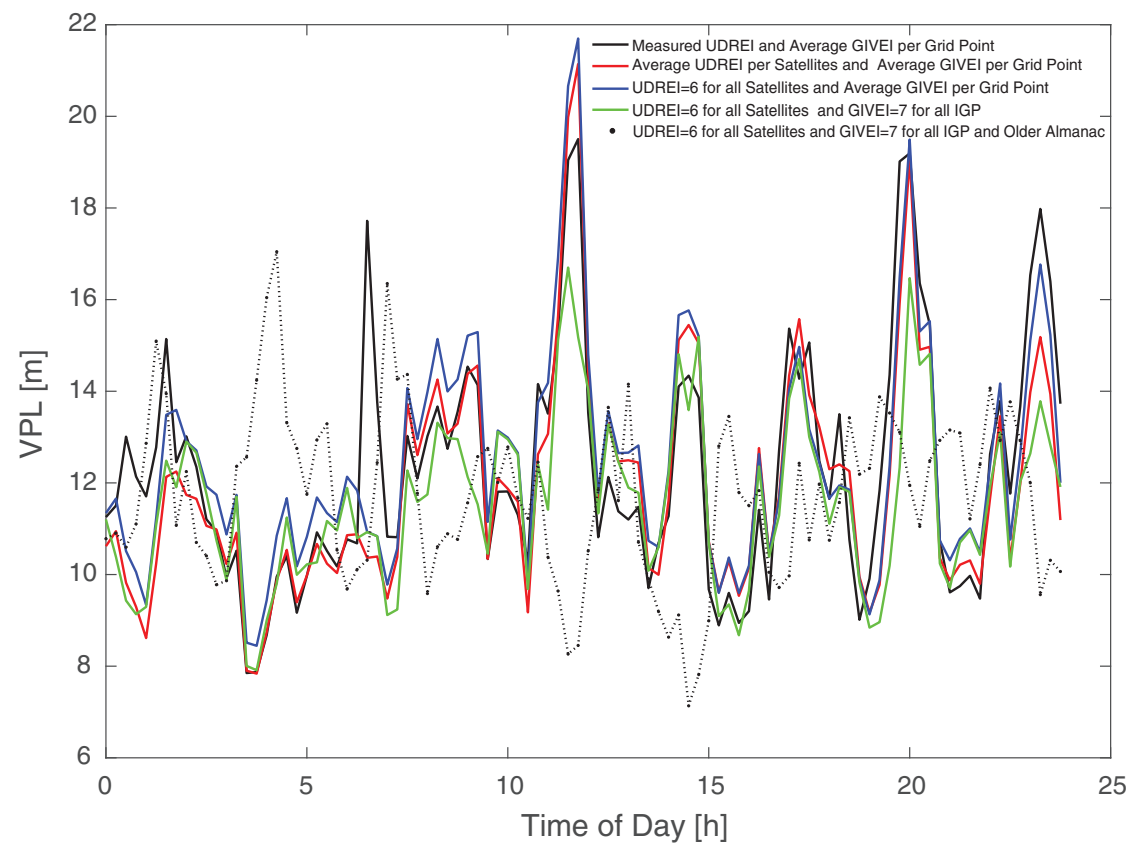

Fig. 5 Comparison of the VPL performance between different prediction methods. 


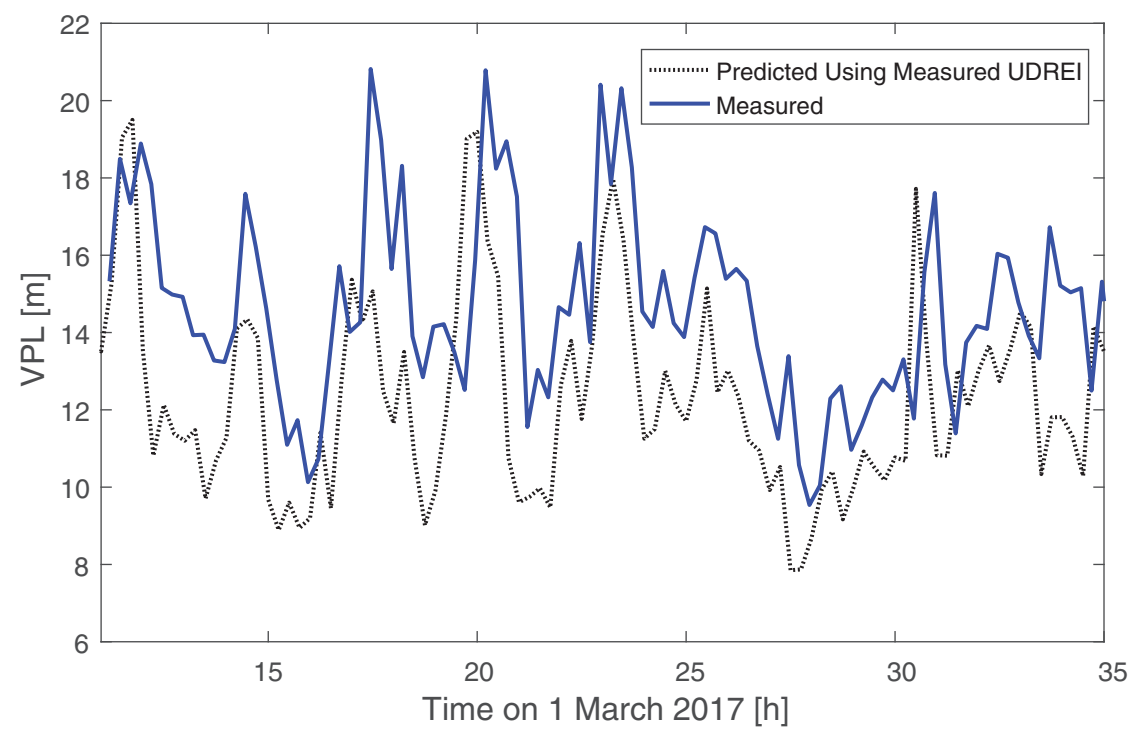

Fig. 6 Measured vs predicted vertical protection levels: GIVEI fixed values, almanac from 1 March 2017, and broadcast UDREI.

Airport compared with a prediction that uses the almanac of March 1 and the UDREI as measured in Innsbruck. We can see that the prediction does come on average within $14.7 \%$ of reality. It is not exactly the same since the prediction uses an average GIVEI per grid point.

We still see $100 \%$ availability of EGNOS LPV200 if the prediction is based on the almanac of March 1 and the measured UDREI (see Fig. 7).

Finally, we ruled out integrity and availability problems by generating Stanford plots with the measured position error and protection level data. These plots are shown in Figs. $\underline{8 a}$ and $\underline{8 b}$, and they confirm that the system operates within the usable and safe range (i.e., actual navigational error bounded by protection levels and protection levels bounded by alert limits).

To evaluate integrity and continuity of an SBAS system, actual navigation performance and protection levels are plotted as a 3-D histogram in an integrity plot. The integrity plot can be divided into four areas: For normal operations, the position error is smaller than the protection level which is in turn smaller than the alert limit (white area). The system is available and overbounding the actual position error correctly. If the protection level is larger than the alert limit the system is unavailable for use (yellow area). Should the position error exceed the protection level, misleading information is given by the system (red/pink area). In case the position error is larger than the alert limit, this misleading

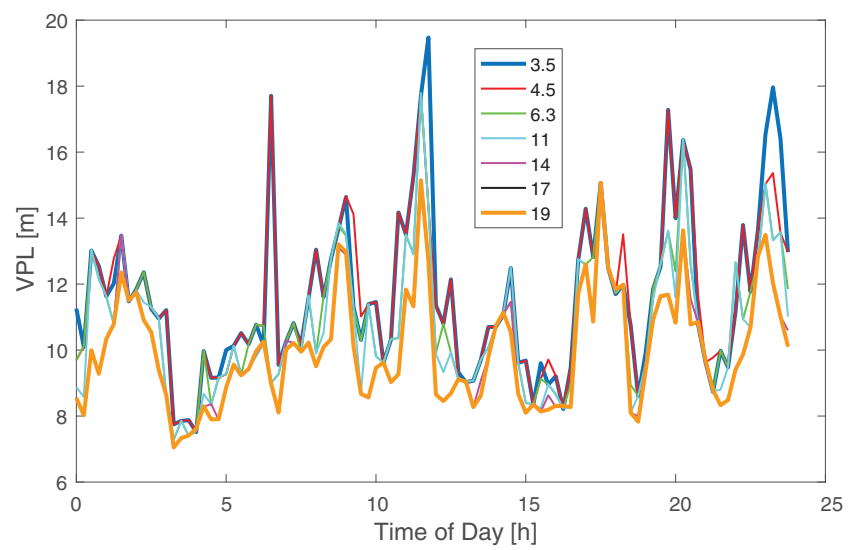

Fig. 7 Vertical protection levels at selected points (DME distances in nautical miles) on approach based on mean GIVEI, almanac data, and UDREI of March 1. Alert limit is, in all cases, $35 \mathrm{~m}$. information becomes hazardous to the aircraft (red area) since no guarantee for it to be within the protected area can be given [1] .

Further information on Stanford plots can be found in Ref. [20]. Overall, all predictions and measurements are in line with the performance required to provide LPV200 service in Innsbruck.

\section{Procedure Design}

The specific design rules applicable to GNSS approaches are promulgated in the second volume of the Procedures for Air Navigation Services-Aircraft Operations (PANS-OPS) [13], including specific criteria for the intermediate, final, and missed approach segments in an SBAS context. These design criteria include the use of more flexible OASs based on a CAT-I precision approach whenever it can be supported by the appropriate service level. The EGNOS LPV200 service level proved sufficient performance in Innsbruck, as described in the previous section. As a result, we applied SBAS CATI procedure design criteria for this first implementation.

It is important to note that, even if CAT-I OASs are used for the design, the obstacle situation determines the obstacle clearance height $(\mathrm{OCH})$, and therefore the type of operations possible after all. Nevertheless, the application of CAT-I design criteria can still be justified due to less stringent protection areas, even if the resulting operations lead to $\mathrm{DH} \geq 250 \mathrm{ft}$, and hence cannot be classified as 3-D approaches of type B CAT-I according to Annex 6 to the Chicago Convention of the ICAO [12].

The initial operational requirements that we defined in cooperation with the relevant stakeholders such as airport operator, air traffic controllers, and airlines can be summarized as follows: the resulting IAP had to be compatible with a procedural separation with visual flight rules traffic within the control zone (CTR), match the current visual precision approach path indicator settings with VPA $=3.5 \mathrm{deg}$, have a final approach segment with a length of around 6-8 n miles and, if possible, include a missed approach that imitates the current RNP-AR approach following the valley west of the runway. Above all, fulfilling these two last requirements posed the biggest challenge to the procedure design team and required certain tradeoff to produce an IAP with reasonable OCHs after many design iterations. Because of massive terrain penetrations in the protection areas, we replaced the straight missed approach path with a turn designated at a waypoint before the runway threshold. Likewise, we calculated an offset (4.7 deg) final approach segment of $9.2 \mathrm{n}$ miles to keep the intermediate approach segment in an area where the aircraft still has enough altitude so as to keep the required minimum obstacle clearance (MOC). Any other attempts to shorten the final approach segment by excluding high terrain features on the sides of the Inn Valley proved 


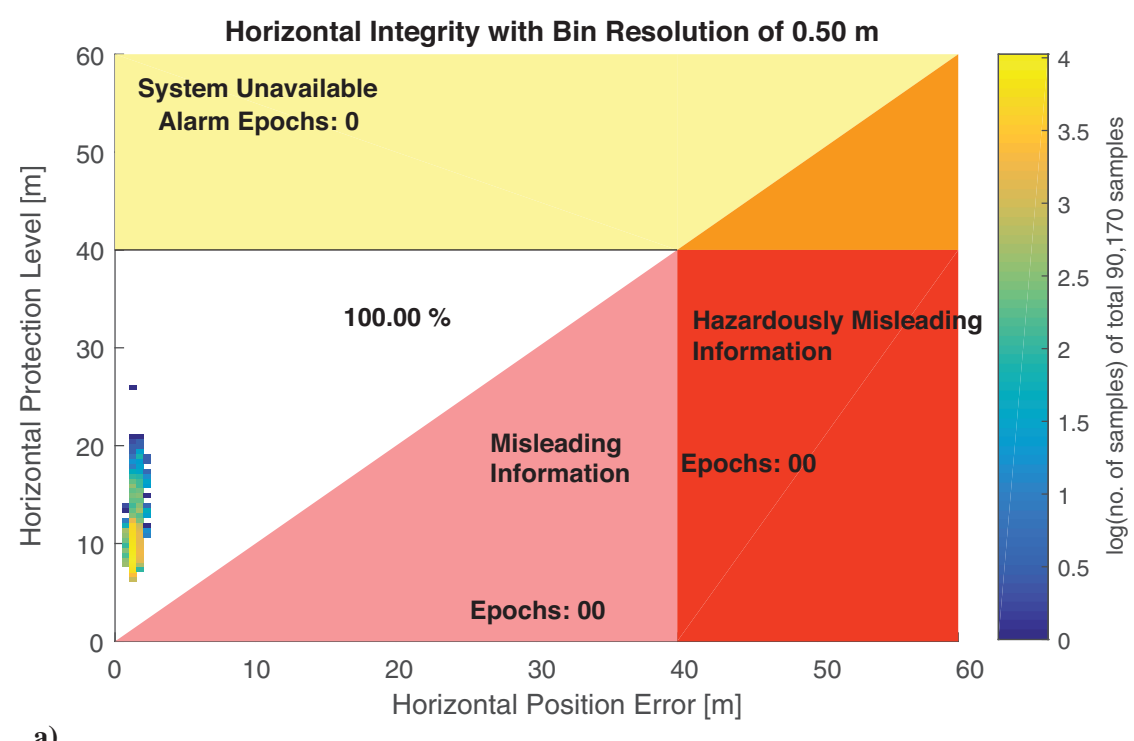

a)

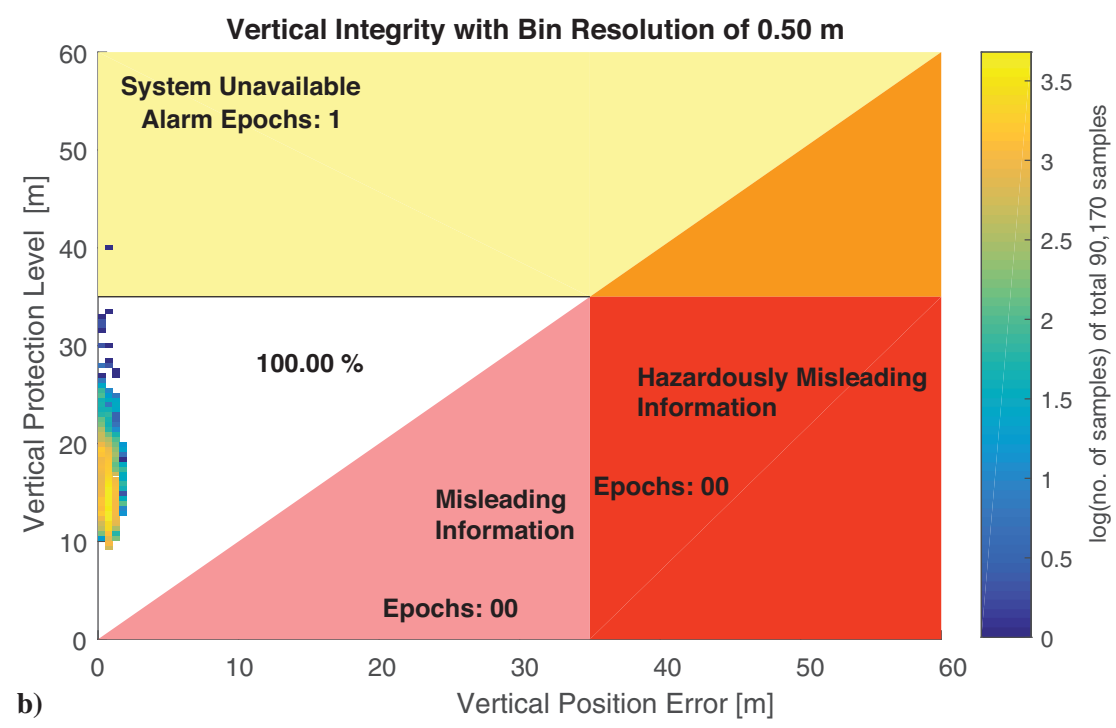

Fig. 8 Stanford diagram of the a) horizontal component and b) vertical component.

unfruitful due to the wide protection areas required by the navigation specification required navigation performance approach (RNP $\mathrm{APCH})$. The final design, including calculated protection areas, can be seen in Figs. 9a and 9b.

We used the dedicated procedure design software Flight Procedure Design and Management from IDS AirNavI in combination with spreadsheets to create protection areas, assess obstructions, and validate the results. To that end, we imported an updated obstacle database and a digital terrain model [21] with a postspacing of approximately $50 \mathrm{~m}$. into the software.

The procedure begins at the initial approach fix (IAF) (WI610) at $9500 \mathrm{ft}$ above mean sea level (AMSL) to facilitate the access via air traffic control (ATC) vectors. The minimum radar vectoring altitude (MRVA) in the area is $9500 \mathrm{ft}$ AMSL. The intermediate fix (IF) (WI612) has a procedural altitude of $6300 \mathrm{ft}$ AMSL. Between the IAF and the IF, the waypoint WI611 serves as a stepdown fix to ensure a safe "dive-and-drive" descent without loss of obstacle clearance in case no continuous descent approach is executed. The procedural altitude at WI611 is $7200 \mathrm{ft}$ AMSL. We draw on procedural altitudes in this design to keep descent gradients within standard ICAO values [13]. Procedural altitudes are always equal or greater than minimum obstacle clearance altitudes.

๑Available online at https://www.idsairnav.com/main-areas/aim/flightprocedure-design/fpdam/ [retrieved 4 June 2020].
To minimize terrain obstructions due to the prominent topographical features of the valley, the intermediate approach segment contains a 28 deg track change to intercept the final approach course before the nominal final approach point (FAP). The overall length of the intermediate segment cannot be longer than $2 \mathrm{n}$ miles for the same reason. As per the ICAO PANS-OPS design criteria [13], the straight component of the segment shall be equal or greater than $2 \mathrm{n}$ miles. The straight component is, in this case, obviously less than $2 \mathrm{n}$ miles due to the required track change at the IF (WI612); its actual length will be variable, depending on individual flight parameters such as radius of turn and bank establishment delay. Nevertheless, a conservative estimate can be derived by applying PANS-OPS minimum stabilization distances [13]. This yields a straight component of $0.8 \mathrm{n}$ miles for the intermediate segment in the worst case (high speed, heavy aircraft). The current design criteria do not consider track changes of less than $50 \mathrm{deg}$, which is the reason why the results are even more conservative and far from reality in this case. This deviation from the design criteria was considered acceptable after the corresponding safety assessment and flight validation.

The semiwidth of the protection areas in the initial and intermediate approach segments is $2.5 \mathrm{n}$ miles, including secondary areas. Secondary areas linearly decrease the full applicable MOC at their inner boundaries to zero at their outer boundaries. The applicable MOC for the initial and intermediate segments are 984 and $492 \mathrm{ft}$, respectively. To account for the switch of the receiver to the SBAS approach mode $2 \mathrm{n}$ miles before the nominal FAP (WI613), the semiwidth of the 


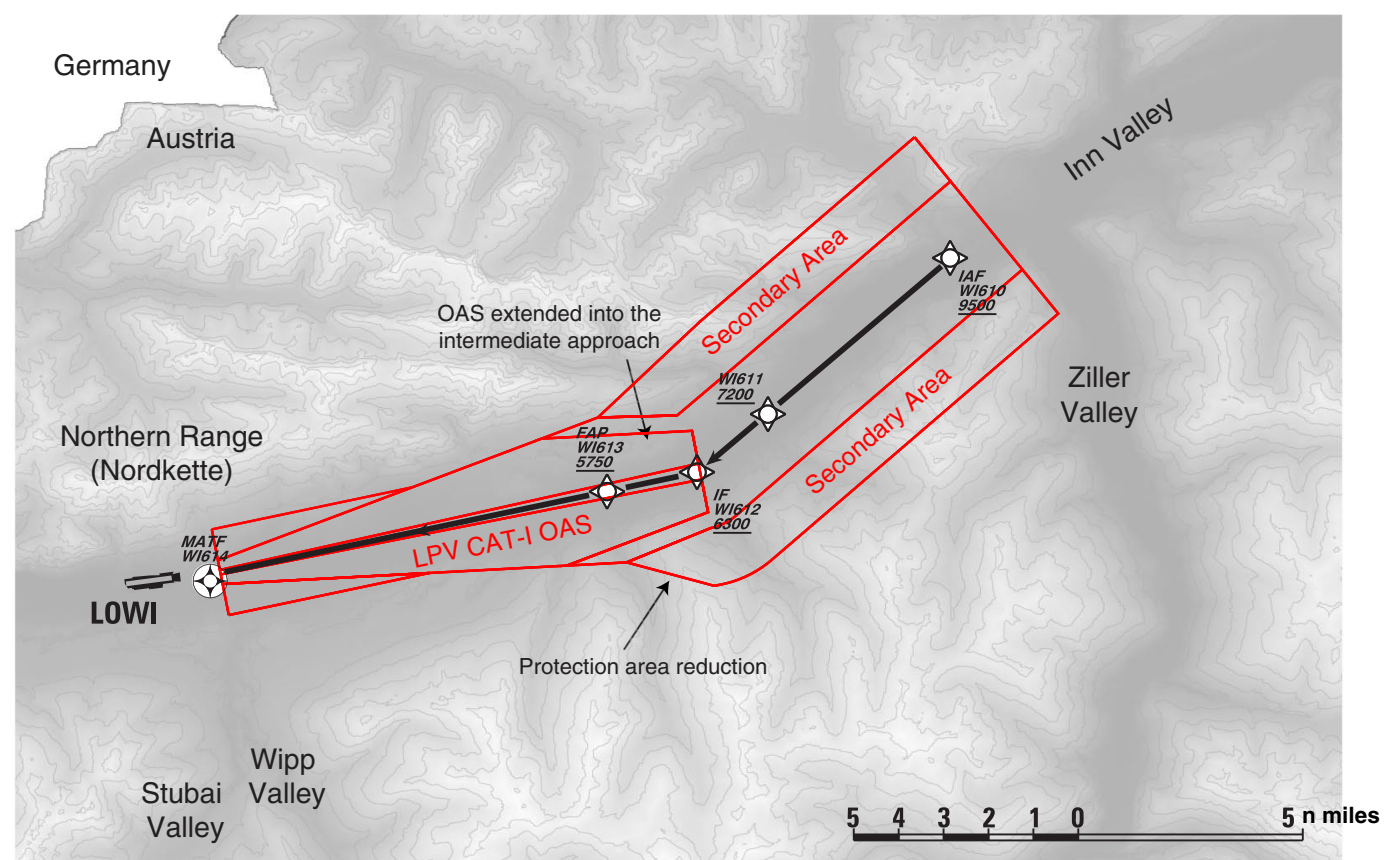

a)

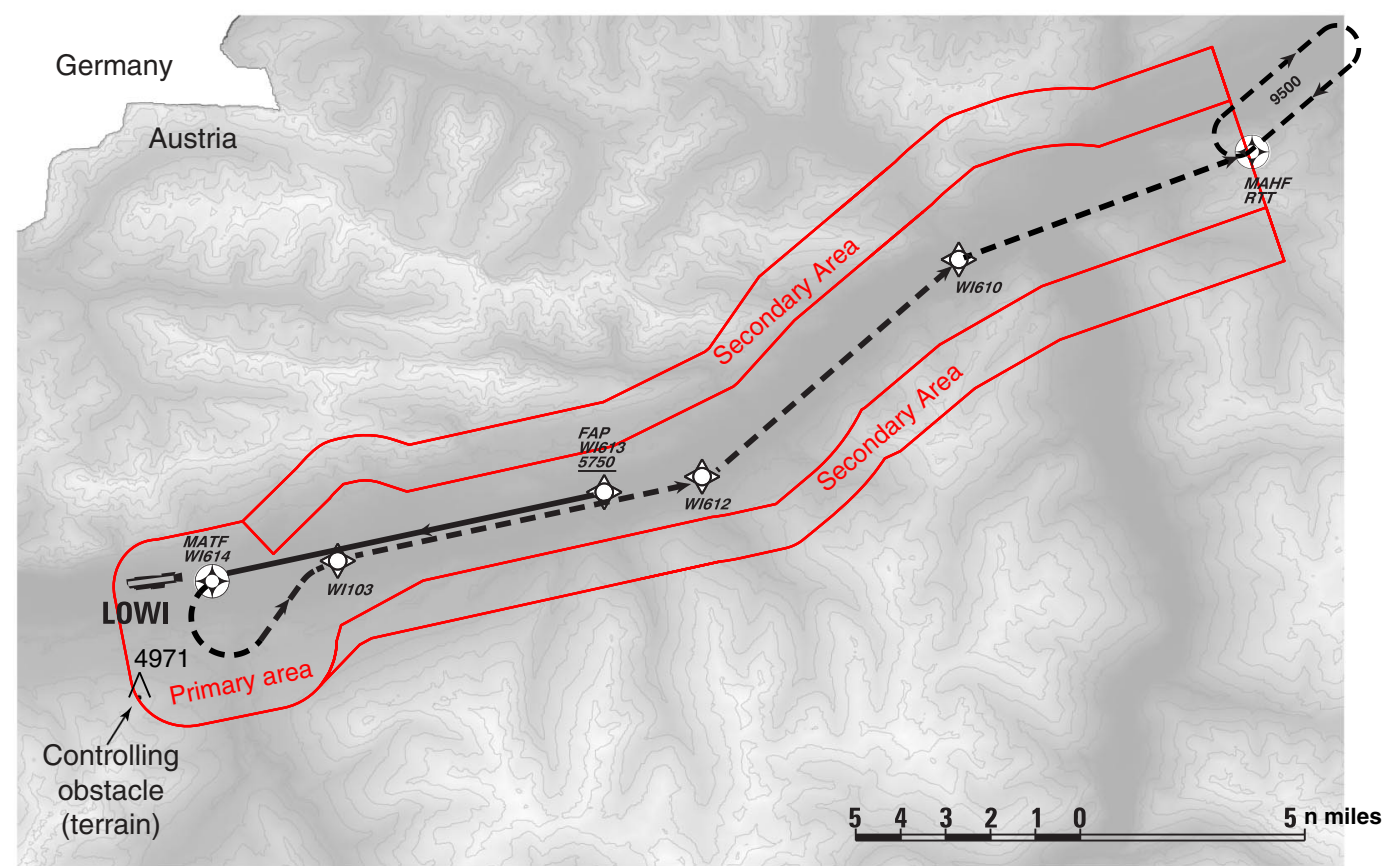

b)

Fig. 9 Procedure tracks and protection areas of initial, intermediate, and final approaches including a) SBAS segment and b) the final missed approach. Note that altitudes and elevations are in feet.

protection areas reduces linearly to join the extension of the CAT-I OASs at the nominal FAP, and the OASs extend into the intermediate segment (see Fig. 9a).

Due to the final approach offset, the geometry of the final approach path is based on a fictitious runway aligned with the final approach track and with a fictitious threshold point (FTP) at the same elevation as the real threshold of RWY26. The GNSS azimuth reference point (GARP) point, equivalent to the conventional localizer antenna, is then set $305 \mathrm{~m}$ after the fictitious runway end to ensure a nominal course width of $105 \mathrm{~m}$ at the FTP (see Fig. 10). This is necessary to provide an appropriate sensitivity of the lateral deviations during final approach. A point lying on the same ellipsoidal plane (GPS height) as the FTP and located at the fictitious runway end acts as a flight-path alignment point (FPAP) and defines the alignment of the final approach segment along with the FTP. A lateral view of a generic final approach segment (FAS) is depicted in Fig. 11. Note that the glide path intercept point (GPIP), which defines the origin of the vertical guidance, is not directly input by the procedure designer into the final approach segment data block, but its coordinates are computed by the SBAS equipment on board by using other main final approach segment parameters. The final approach segment data

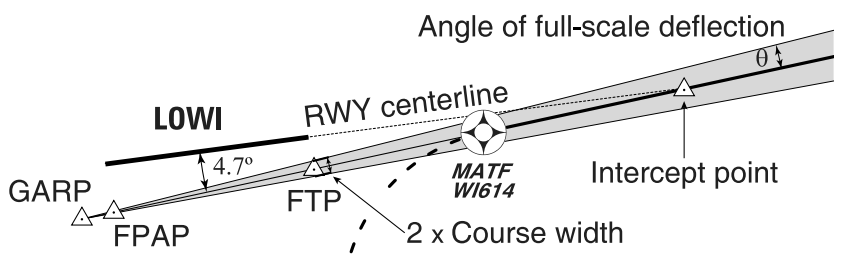

Fig. 10 Top view of the final approach segment geometry corresponding to the LPV approach to RWY26 in Innsbruck. 


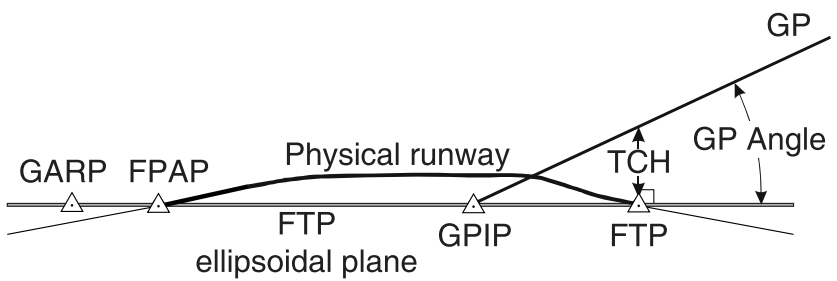

Fig. 11 Lateral view of a generic FAS (based on Ref. [13]).

block is a set of parameters, which contain all necessary information for the aircraft to calculate deviations relative to the desired final approach segment. It is described in Ref. [13] with the key parameters being the landing threshold point, the glide path (GP) angle, the threshold crossing height (TCH), and the full-scale course deviation indicator, given by the GARP and the course width or absolute lateral deviation when crossing the landing threshold. We used the EUROCONTROL SBAS FAS Data Block online tool [22] to encode the final approach segment data block out of the many design inputs (see Table 1).

The height loss concept, widely used in 3-D approaches such a s ILS and baro-VNAV [13], is applied as well to calculate the OCH within the precision segment spanning from the nominal FAP to the missed approach turning fix (MATF) (WI614). The OASs are identical to those of an ILS CAT-I, with the only difference that the side surfaces $Y$ are always contained in a corridor with a semiwidth of $0.95 \mathrm{n}$ miles to protect for an early missed approach, triggering a premature switch from angular to linear guidance (see Fig. 9a).

The position of the MATF (WI614) that initiates the final phase of the missed approach with a 180 deg turn is key to reach a reasonable $\mathrm{OCH}$. High terrain obstructions on the side of the valley fall inevitably within the turn area. Only a thorough iterative selection of the waypoint coordinates on the order of meters led to the best OCHs possible for different missed approach (MA) climb gradients. The final location of the MATF enables the turn at a point where the width of the Inn Valley makes it feasible. In this turn area, the Inn Valley intersects with the Wipp Valley in the south (see Fig. 9b).

Two important design considerations of the current criteria for this type of procedure have to be taken into account when selecting the final position of the MATF. The first one is related to the existing

Table 1 FAS Data Block for the LPV approach to RWY26 at Innsbruck International Airport (Austria)

\begin{tabular}{lc}
\hline \hline Name & Value \\
\hline Operation TYPE & 0 \\
SBAS Provider & 1 \\
Airport identifier & LOWI \\
Runway & 26 \\
Runway direction & 0 \\
Approach performance designator & 0 \\
Route indicator & $\mathrm{E}$ \\
Reference path data selector & 0 \\
Reference path identifier & $\mathrm{E} 26 \mathrm{~A}$ \\
Landing threshold point (LTP) latitude & $471532.2960^{\circ} \mathrm{N}$ \\
LTP longitude & $0112128.0660^{\circ} \mathrm{E}$ \\
LTP ellipsoidal height, $\mathrm{m}$ & 626.0 \\
FPAP Latitude & $471517.7745^{\circ} \mathrm{N}$ \\
Delta FPAP latitude, $\mathrm{s}$ & -14.5215 \\
FPAP longitude & $0112000.3950^{\circ} \mathrm{E}$ \\
Delta FPAP longitude, $\mathrm{s}$ & -87.6710 \\
TCH, ft & 50.0 \\
TCH units selector & 0 \\
Glide-path angle, deg & 3.49 \\
Course width, $\mathrm{m}$ & 105.00 \\
Length offset, $\mathrm{m}$ & 0 \\
HAL, $\mathrm{m}$ & 40.0 \\
VAL, $\mathrm{m}$ & 35.0 \\
Calculated cyclic redundancy check & $53 \mathrm{~B} 35640$ \\
ICAO code & $\mathrm{LO}$ \\
LTP/FTP orthometric height, $\mathrm{m}$ & 577.0 \\
FPAP orthometric height, $\mathrm{m}$ & 577.0 \\
\hline \hline
\end{tabular}

offset with respect to the extension of the runway centerline. According to PANS-OPS, the intercept point between the offset segment and the extension of the RWY centerline (see Fig. 10) has to reach a height of at least $180 \mathrm{ft}$ above threshold. In our procedure, this intercept height is $790 \mathrm{ft}$ above threshold. The lowest $\mathrm{OCH}$ allowed without considering obstacles is then calculated by adding $66 \mathrm{ft}$, which yields $856 \mathrm{ft}$. On the other hand, the position of the MATF and its associated along-track tolerance (ATT) of $0.24 \mathrm{n}$ miles are of paramount importance because they define the beginning of the turn area that protects for the latest turn possible. To reduce the portion of high terrain obstructions captured by the turn area, a limitation on the radius of turn in still air is necessary. The radius of turn can be expressed as $R=\left(V^{2} / g \tan \alpha\right)$, assuming a uniform stationary turn, where $V$ represents true airspeed (TAS), $g$ is the acceleration due to gravity, and $\alpha$ is the bank angle. The radius of turn is then used in combination with the effect of an omnidirectional wind factor of $30 \mathrm{kt}$ to determine the drift of the outermost trajectory throughout the turn, which is also known as wind spiral (see Fig. 12). We established a maximum turn radius of $0.9 \mathrm{n}$ miles by limiting the indicated air speed (IAS) to a maximum of $153 \mathrm{kt}$ and demanding a bank angle of at least $25 \mathrm{deg}$ during the missed approach turn. An IAS of $153 \mathrm{kt}$ corresponds to a TAS of approximately $169 \mathrm{kt}$ at the highest point possible of all nominal turns calculated for the various climb gradients and assuming a positive variation to the International Standard Atmosphere of $15^{\circ} \mathrm{C}$. The restriction on the bank angle during the missed approach turn is a clear deviation to PANS-OPS design criteria [13], which foresee a bank angle of $15 \mathrm{deg}$ for this phase of flight. This bank angle limitation is currently promulgated during the missed approach turn of the LOC/DME approach to the same runway and was likewise considered acceptable after the corresponding safety assessment and flight validation. According to the design criteria, the earliest missed approach turn (MATF-ATT) has to be coincident with the latest start of climb (SOC) to avoid turns with negative vertical speed (see Fig. 12). The SOC is the point at which the aircraft begins to climb after initiating a go-around. This results in the lowest SOC being possible at the point where $548 \mathrm{ft}$ above RWY threshold are reached along the final approach path. For Aircraft Approach Category $\mathrm{C}(\mathrm{CAT}-\mathrm{C})$ operations, and considering the penalty added to the corresponding height loss for VPA $>3.2 \mathrm{deg}$, the lowest possible $\mathrm{OCH}$ for the procedure would be $712 \mathrm{ft}$. These two limitations are below the OCH imposed by the controlling obstacle for the different missed approach climb gradients published (see the minima box on the bottom left-hand side of the chart in Fig. 13) but may be the limiting factor if smaller protection areas can be applied for the missed approach at some point in the future.

After the first missed approach turn at WI614, the procedure guides the aircraft back along the valley up to the holding fix of Rattenberg (RTT), where $11,500 \mathrm{ft}$ AMSL are required to provide enough separation with inbound traffics while flying the holding pattern.

\section{Safety Assessment and Flight Inspection}

EGNOS is an extremely accurate navigation system. It is composed of satellites and ground stations that improve the accuracy of the Global Navigation Satellite System. The "ILS-lookalike" procedures can be seen as the most significant backup procedure for ILS in

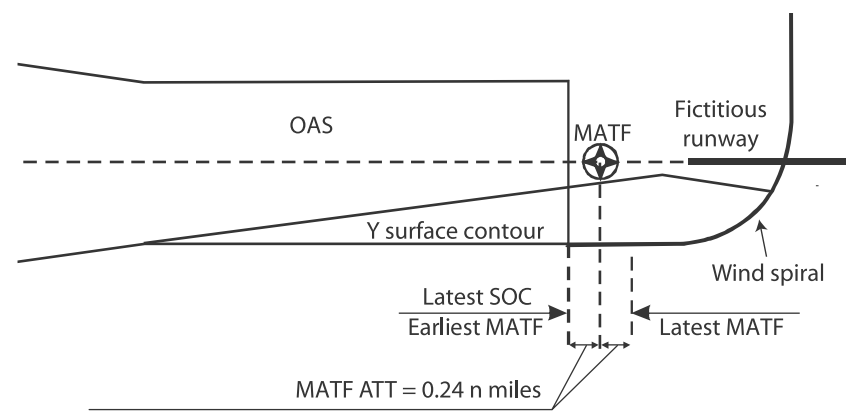

Fig. 12 Construction of the missed approach turn before the runway threshold (based on Ref. [13]). 


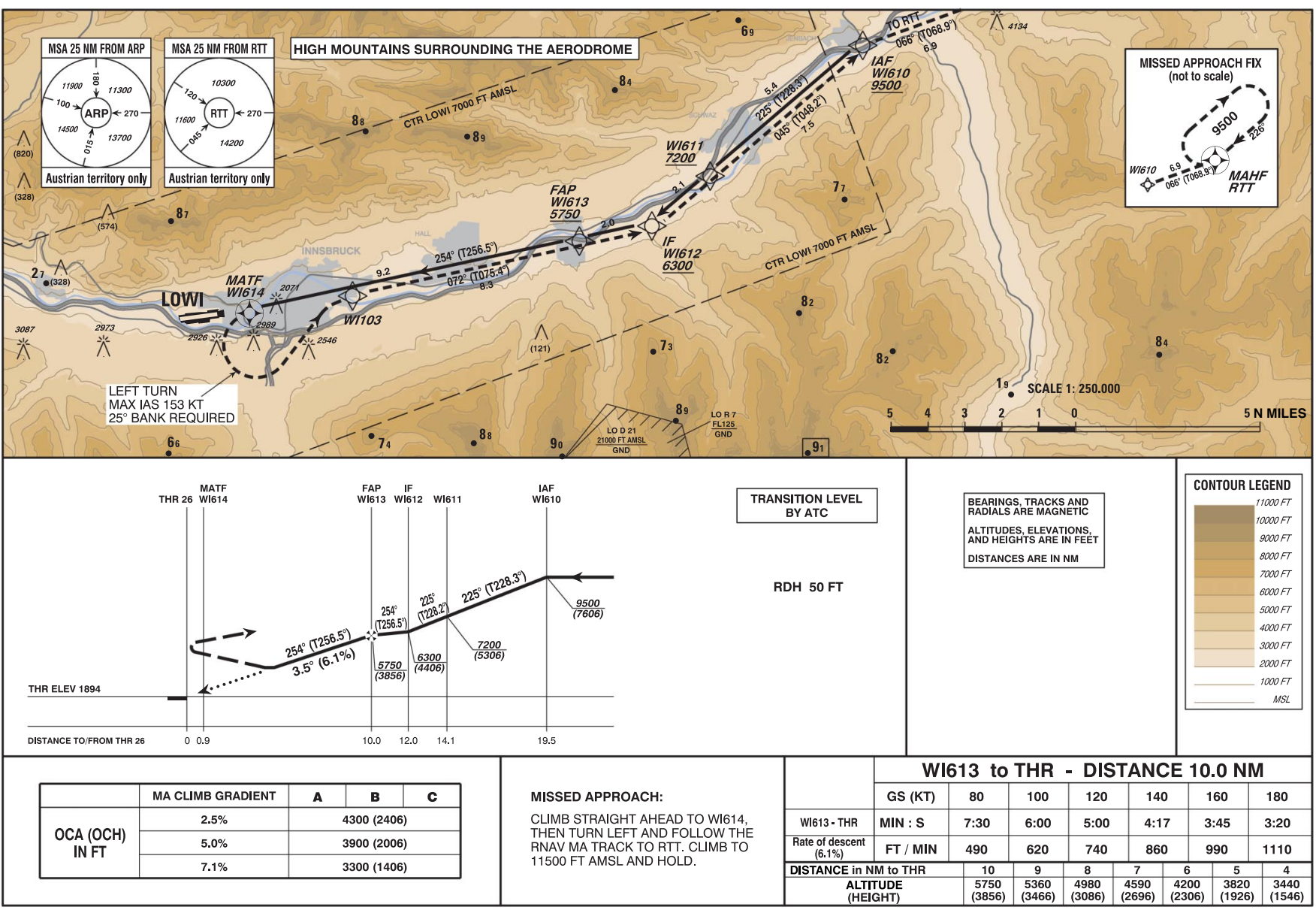

Fig. 13 Chart of the LPV approach to RWY 26 in Innsbruck (AIP Austria: effective date 21 June 2018; Austro Control, GmbH @).

Austria, especially for a large group of general aviation aircraft that cannot fly barometric VNAV approaches, and therefore only gains vertical guidance in GNSS approaches by means of SBAS. SBAS service does not require the installation or maintenance of groundbased landing system navigation aids. The SBAS augmented position and guidance do not change with barometric and temperature fluctuations, and they are not impacted with an improper aircraft barometric altimeter setting. Besides the general approval of SBAS as a landing aid in Annex 10 [14], the ICAO requires that each published instrument approach undergoes a procedure specific safety assessment. EUROCONTROL has already developed a generic concept of operations [23] for APV SBAS approach procedures in which a series of minimum requirements are identified. In addition, Ref. [24] released generic safety case guidance material for LPV approaches to a $200 \mathrm{ft}$ decision height. To complete the safety assessment and, complementing Ref. [24] for Innsbruck, we assessed the hazards for the LPV procedure to be implemented in Table 2. Here, we identify the operational function, hazard cause, and existing and additional mitigation actions. The pre- and postmitigation action severity classes are indicated. The appendix to the Austrian Air Navigation Services (ANS) Safety Regulatory Framework defines the acceptable risk severity for air navigation services in order to enable a quantitative risk-based approach fulfilling the requirements of the European commission (EC) regulation no. 2096/2005. The target levels of safety for Austro Control are as follows:

1) Contributing to an accident of a commercial airplane is severity class 1

2) Contributing to a serious incident of a commercial airplane is severity class 2

3) Contributing to a major incident of a commercial airplane is severity class 3

4) Contributing to a significant incident of a commercial airplane is severity class 4
5) No direct contribution to safety occurrences is severity class 5 Table 2 only shows the additional hazards that are nongeneric to LPV procedures, or for which Austro Control has defined additional mitigation actions. All others can be found in Ref. [24] and are not repeated here. When the EGNOS safety of life service is not available, or when the GPS constellation does not support the LPV approach, Austro Control will issue notices to airmen to advise pilots. They must then fly another approach procedure. Flight crews that use LPV equipment are expected to have completed training about this type of approach and are sufficiently confident in handling it. Furthermore, it is expected that the database that is loaded into the aircraft navigation system is current and complete. Aircraft have to be certified for SBAS operation in accordance with the European Aviation Safety Agency's (EASA's) Acceptable Means of Compliance (AMC) 20-28 [25] or the last issue of EASA Certification Specifications and Acceptable Means of Compliance for Airborne Communications, Navigation and Surveillance (CS-ACNS) [26]. The safety assessment was positively reviewed by three independent experts in the areas of air traffic control, flight operations, and airworthiness, respectively.

For the procedure to be published in the national Aeronautical Information Publication (AIP), it has to be properly flight inspected and validated according to volume 2 of ICAO document 8071 [27], as well in line with volume 5 of ICAO document 9906 [28]. Both documents provide the complete methodology for performing flight validation and flight inspection of instrument flight procedures. To get an overview of the techniques involved, we provide the three most important examples from the flight-test report in the following paragraph.

For flight inspection, data house Jeppesen provided a trial navigation database in raw Aeronautical Radio, Incorporated (ARINC) 424 format [29] to Flight Calibration Services (FCS)-: a German

\footnotetext{
**Data available online at https://www.fcs.aero/.
} 
Table 2 Safety assessment table specific for the Innsbruck Airport

\begin{tabular}{|c|c|c|c|c|c|c|c|}
\hline Function & Hazard and cause & Current risk minimization & $\begin{array}{c}\text { Worst case operational } \\
\text { consequence }\end{array}$ & Severity & $\begin{array}{c}\text { Safety } \\
\text { goal }\end{array}$ & $\begin{array}{l}\text { Additional risk } \\
\text { minimization }\end{array}$ & Postseverity \\
\hline $\begin{array}{l}\text { EGNOS signal } \\
\text { in } \\
\text { mountainous } \\
\text { terrain }\end{array}$ & Loss of satellites/signal & $\begin{array}{l}\text { Quality assessment of } \\
\text { GPS/EGNOS signal } \\
\text { through simulations and } \\
\text { measurements on site } \\
\text { Application of SBAS was } \\
\text { possible }\end{array}$ & Missed approach & 4 & -- & N/A & 4 \\
\hline $\begin{array}{l}\text { Loss of GNSS/ } \\
\text { EGNOS signal } \\
\text { during final } \\
\text { approach or } \\
\text { missed } \\
\text { approach } \\
\text { phase }\end{array}$ & $\begin{array}{l}\text { Troubles with GNSS or } \\
\text { EGNOS signal; loss of } \\
\text { satellites/jamming/ } \\
\text { problems with equipment }\end{array}$ & $\begin{array}{l}\text { Pilot should initiate } \\
\text { contingency procedure } \\
\text { radar vectoring- } \\
\text { surveillance coverage } \\
\text { available at all Austrian } \\
\text { airports }\end{array}$ & $\begin{array}{l}\text { Use non-GNSS } \\
\text { approach }\end{array}$ & 4 & $\begin{array}{l}\text { No } \\
\text { greater } \\
\text { than } \\
\text { before }\end{array}$ & $\begin{array}{l}\text { Safety recommendation: } \\
\text { briefing ATCOs radar } \\
\text { vectoring-in case the } \\
\text { aircraft is still at or above } \\
\text { the MRVA/SMA }\end{array}$ & 5 \\
\hline $\begin{array}{l}\text { Procedure } \\
\text { design }\end{array}$ & $\begin{array}{l}\text { Two deviations from } \\
\text { ICAO DOC } 8168 \text { [13]: } \\
\text { minimum bank angle in } \\
\text { the missed approach } \\
\text { greater than } 15 \mathrm{deg}, \\
\text { straight leg in } \\
\text { intermediate segment less } \\
\text { than } 2 \mathrm{n} \text { miles }\end{array}$ & $\begin{array}{l}\text { Procedure properly } \\
\text { validated according to } \\
\text { ICAO DOC } 9906[28]\end{array}$ & $\begin{array}{l}\text { Minimum bank angle: } \\
\text { aircraft gets outside } \\
\text { area for which } \\
\text { procedure is not } \\
\text { protected Intermediate } \\
\text { segment: final } \\
\text { approach course } \\
\text { wrongly intercepted }\end{array}$ & 3 & $\begin{array}{l}\text { No } \\
\text { greater } \\
\text { than } \\
\text { before }\end{array}$ & $\begin{array}{l}\text { Safety recommendation, } \\
\text { flight validation: } \\
\text { approach was positively } \\
\text { evaluated in VMC, } \\
\text { which endorsed } \\
\text { proposed design Safety } \\
\text { recommendation, } \\
\text { intensive testing in an } \\
\text { experimental simulator } \\
\text { to discard flyability } \\
\text { issues even under } \\
\text { extreme wind conditions } \\
\text { successful }\end{array}$ & 4 \\
\hline $\begin{array}{l}\text { Minima lines } \\
\text { on the } \\
\text { published } \\
\text { chart do not } \\
\text { distinguish } \\
\text { between LPV } \\
\text { or LPV200 } \\
\text { operations }\end{array}$ & $\begin{array}{l}\text { Where both minima } \\
\text { criteria coexist, operators } \\
\text { may mix the system } \\
\text { minima, leading to a } \\
\text { situation where a DH } \\
\text { below } 250 \mathrm{ft} \text { is considered } \\
\text { for LPV based on APV-I } \\
\text { criteria }\end{array}$ & $\begin{array}{l}\text { Since published minima } \\
\text { by Austro Control in form } \\
\text { of OCH are already equal } \\
\text { to or greater than } 250 \mathrm{ft} \text { for } \\
\text { LPV approaches based on } \\
\text { APV-I criteria at target } \\
\text { airports, there is no risk } \\
\text { for operators confusing } \\
\text { operating minima }\end{array}$ & Increased collision risk & 4 & $\begin{array}{l}\text { No } \\
\text { greater } \\
\text { than } \\
\text { before }\end{array}$ & N/A & 4 \\
\hline
\end{tabular}

N/A = not available

ATCO = Air Traffic Control Officer

VMC $=$ Visual Meteorological Conditions

APV-1 = Approach Performance with Vertical guidance one

SMA = Surveillance Minimum Altitude

professional flight validation and inspection company. In the first step of validation, FCS reviewed the received experimental navigation database for potential coding mistakes that could have occurred when transferring AIP data into the specific ARINC424 database format. Here, it was found that the turn direction toward WI613 was missing from the coding, and a typographic error pertaining to the waypoint's coordinates was discovered. This was consequently corrected by the provider. Next, the database was loaded into the Aerodata AD-AFIS220 flight inspection system of the flight inspection aircraft with registration D-CFMD: a Beech 300 Super King Air 350. The Aerodata AFIS-220 calculates a precise reference position using a hybrid solution of barometric altitude, inertial platforms, and a precision differential GNSS. The GNSS data were recorded at $1 \mathrm{~Hz}$. Flight validation was successfully completed on 3 June 2017 from 1058 to
1119 hrs Universal Time Coordinated (UTC). The weather was good, with variable wind direction and wind strength of $2 \mathrm{kt}$. Visibility was more than $10 \mathrm{~km}$, scattered clouds were $7000 \mathrm{ft}$ above the aerodrome, and the temperature was $26^{\circ} \mathrm{C}$. Sea level pressure was $1015 \mathrm{hPa}$. Section 5.3 of Ref. [27] required the procedure navigation accuracy to be verified according to procedure design requirements, as specified in Ref. [13]. The requirements are a required crosstrack navigation performance ( $95 \%$ confidence interval) of $1 \mathrm{n}$ mile in the initial and intermediate approach segments, and tapering to $0.3 \mathrm{n}$ miles for the final approach segment, where the angular guidance calculation begins. For the final approach according to LPV, the total system error may not exceed more than half of the full-scale deflection. The navigation sensor error (NSE) should not exceed the horizontal alert limit of $40 \mathrm{~m}$ and the vertical alert limit of $35 \mathrm{~m}$. During the flight

Table 3 Coding table used for LPV approach to RWY26 at Innsbruck International Airport (Austria) ${ }^{\mathrm{a}}$

\begin{tabular}{|c|c|c|c|c|c|c|c|}
\hline Point & Leg & Latitude & Longitude & Distance, $\mathrm{n}$ miles & Course & Altitude, $\mathrm{ft}$ & Remarks \\
\hline WI610 (IAF) & IF & N472322.41 & E0114654.41 & -- & -- & $+9,500$ & -- \\
\hline WI611 & $\mathrm{TF}$ & N471944.76 & E0114055.80 & 5.4 & T228.3 & $+7,200$ & -- \\
\hline WI612 (IF) & $\mathrm{TF}$ & N471821.49 & E0113838.95 & 2.1 & T228.2 & $+6,300$ & -- \\
\hline WI613 (FAP) & $\mathrm{TF}$ & $\mathrm{N} 471753.55$ & E0113547.48 & 2.0 & T256.5 & $+5,750$ & -- \\
\hline WI614 (MATF) & $\mathrm{TF}$ & N471544.57 & E0112242.29 & 9.2 & $\mathrm{~T} 256.5$ & -1 & Flyover \\
\hline WI103 (MATF) & $\mathrm{DF}$ & N471616.49 & E0112647.56 & -- & -- & -- & $\mathrm{IAS} \leq 153 \mathrm{kt}$, bank $\geq 25 \mathrm{deg}$ \\
\hline WI612 (MATF) & $\mathrm{TF}$ & N471821.49 & E0113838.95 & 8.3 & T075.4 & -- & -- \\
\hline WI610 (MATF) & $\mathrm{TF}$ & N472322.41 & E0114654.41 & 7.5 & T048.2 & -- & -- \\
\hline RTT (MAHF) & $\mathrm{TF}$ & N472551.32 & E0115624.19 & 6.9 & T068.9 & $+11,500$ & Flyover \\
\hline
\end{tabular}

aThe navigation specification used is RNP APCH.

$\mathrm{TF}=$ Track to Fix, DF = Direct to Fix, and IF = Initial Fix. 
inspection, the AD-AFIS-220 measured a average crosstrack total system error from the designed path of $-0.079 \mathrm{n}$ miles with a standard deviation of $0.262 \mathrm{n}$ miles by comparing the precision differential GNSS position with the one provided by the standard avionics. The total system error is the addition of the ability of the aircraft to follow a desired path combined with the error of the navigation sensor NSE. These values are fully within the limit of $1 \mathrm{n}$ mile for initial and intermediate approaches. For the LPV final approach, the maximum vertical deviation reached $2.1 \%$ of full scale, and the maximum lateral deviation reached $0.3 \%$ of full scale. The final approach during flight inspection lasted $140 \mathrm{~s}$, and lateral deviation data were sampled at $10 \mathrm{~Hz}$. The maximum NSE during that time was $4.5 \mathrm{~m}$ horizontal and $0.76 \mathrm{~m}$ vertical as measured with the precision differential GNSS.

Section 2.3.1 of Ref. [27] requires the verification of adequate GNSS signal reception. This is accomplished by measuring the signal's carrier to noise ratio at the receiver front end [14]. Section 3.7.3.1.7.4 defines the adequate reception power of GNSS satellites to be above $-158.5 \mathrm{~dB} \cdot \mathrm{W}$. GNSS receivers usually measure carrier to noise ratio as a quality indicator of the received signal [30]. Typical thermal noise $N$ at the surface of the Earth at $15 \mathrm{deg}$ is

$$
N=k_{B} T=3.98 \times 10^{-21} \mathrm{~W} / \mathrm{Hz}=-204 \mathrm{~dB} / \mathrm{Hz}
$$

Reference [14] stipulates a $3 \mathrm{~dB}$ gain in the antenna. Therefore, a rough estimate for the minimum carrier to noise density ratio is

$$
C / N_{0}=-158.5 \mathrm{~dB} \cdot \mathrm{W}-(-204 \mathrm{~dB} / \mathrm{Hz})-3 \mathrm{~dB}=42.5 \mathrm{~dB} / \mathrm{Hz}
$$

The receiver front end design is a trade secret of each receiver manufacturer, and thus not publicly available. Note that advanced receiver technologies permit a tracking of satellites using a much lower carrier to noise ratio for the same received signal power. Hence, we stipulate that our approach to transferring ICAO requirements to carrier to noise ratio is very conservative. Carrier to noise data were collected during one approach from a time stamp of 39,692 s of the day to a time stamp $40,030 \mathrm{~s}$. This yields a total measuring time of $338 \mathrm{~s}$. At a $1 \mathrm{~Hz}$ sampling and tracking a total of nine GPS satellites, we collected 3051 samples. The mean value was $47.7 \mathrm{~dB} / \mathrm{Hz}$ and the standard deviation was $1.4 \mathrm{~dB} / \mathrm{Hz}$. During the validation, the signal to noise ratio over all nine GPS satellites was ranging from $44.1 \mathrm{~dB} / \mathrm{Hz}$ at an elevation of $30.2 \mathrm{deg}$ to $50.57 \mathrm{~dB} / \mathrm{Hz}$ at an elevation of $66.1 \mathrm{deg}$. The SBAS signals were received with $46.047 \mathrm{~dB} / \mathrm{Hz}$. Thus, the signal reception is adequate, and it indicates that there is no signal degradation due to interference. Of course, the flight validation provides only a snapshot of signal measurements. It is intended for the certifying authority to see that all the technology is functional. For this purpose, the data collection during one approach is adequate. More data would result in statistically more meaningful results, but flight time is costly; and, a statistically meaningful campaign to, for example, validate integrity at a $10^{-5}$ would require at least 100,000 samples. At $1 \mathrm{~Hz}$, this amounts to $27.8 \mathrm{~h}$ of flight data, which are too expensive for implementing a single approach. The flight validation report is provided as Supplemental Material.

\section{Conclusions}

The final procedure design is materialized through the corresponding coding table and chart shown in Table $\underline{3}$ and Fig. 13 , respectively. The coding table contains a textual description of the sequence of ARINC424 path terminators required by flight management systems. Further information on path terminators and ARINC424 coding rules can be found in Ref. [29]. SBAS approach procedures also require the final approach segment data block, which encodes the geometry of the final approach path (see Table 1) into 21 fields including the cyclic redundancy check integrity field as per ICAO Annex 10 [14]. The combination of the coding table and final approach segment data block is of utmost importance because it conveys the procedure designer's intent to the end user. A small error in these datasets may result in a different approach path definition for which obstacle clearance is not provided. The outcome of the flight inspection confirmed the positive results of the signal availability measurements and simulations. During the flight validation, the aircraft was forced to fly close to the edges of the protection areas to detect potential obstacle-related hazards. This can be done by flying the final and missed approaches at a slight higher speed, a lower missed approach climb gradient, and a minimum bank angle for a given DH. The results endorsed the two design criteria deviations and confirmed a good flyability. Despite the many challenges posed by the mountainous terrain in Innsbruck, it was shown that an SBAS CAT-I precision approach can be designed even where ILS approaches could not be implemented in the past.

A proper signal assessment to ensure availability for the required operational service level is key to a successful implementation in environments with complex terrain. The methods described in the Signal Analysis section (Sec. II) may be applied to other airports where signal reception and GNSS performance are unclear at the beginning of LPV implementation. Likewise, a thorough procedure design with many iterations may be necessary to find the optimum set of design parameters that makes the approach flyable. In this regard, the flight validation plays a critical role, especially if the procedure contains deviations to the standard design criteria.

Nevertheless, LPV approaches still require relatively large protection areas for mountainous environments. Authorization required procedures may be necessary to achieve a considerable reduction of the landing minima, thereby increasing accessibility, but only to a few operators. As shown here, the operational benefits of the more stringent SBAS CAT-I approaches (with vertical alert limit of $35 \mathrm{~m}$ ) cannot be gained if the controlling obstacle is not located within the precision segment. Thus, SBAS APV approaches may sometimes be a better option over SBAS CAT-I in areas with challenging terrain. This can be critical in environments where average protection levels fluctuate right underneath the alert limits, thus raising the likelihood of persistent integrity events. However, this does not seem to be the case of Innsbruck for the time being. Therefore, in order to maximize availability, the implementation of legacy SBAS APV approaches is advocated in mountainous terrain if the corresponding SBAS CAT-I approach cannot bring along a significant operational benefit.

\section{Acknowledgments}

This work was performed in the frame of the project called IMPROWE [which stands for Implementing Required Navigation Performance Approach Operations with the European Geostationary Navigation Overlay Service (EGNOS)], funded by the European Global Navigation Satellite System Agency (GSA) under grant agreement GSA/GRANT/EGNOS/03/2014-12 of the GSA called "Acceleration of EGNOS Adoption in the Field of Civil Aviation." We would like to thank the air traffic services unit of Innsbruck and the entire Austro Control Instrument Flight Procedure (IFP) and Static Data Management (SDM) teams for making possible the publication of the first satellite-based augmentation system instrument landing system lookalike approach in Innsbruck. We are also grateful to the Flight Calibration Services crew that flight validated the procedure and to the many pilots that provided invaluable feedback. Finally, we would like to thank the German Aerospace Center (DLR) personnel of the Institute of Flight Guidance for the guidance and support during the flight simulation sessions.

\section{References}

[1] Dautermann, T., "Civil Air Navigation Using GNSS Enhanced by Wide Area Satellite Based Augmentation Systems," Progress in Aerospace Sciences, Vol. 67, May 2014, pp. 51-62. https://doi.org/10.1016/j.paerosci.2014.01.003

[2] Dautermann, T., Mollwitz, V., Többen, H. H., Altenscheidt, M., Bürgers, S., Bleeker, O., and Bock-Janning, S., "Design, Implementation and Flight Testing of Advanced RNP to SBAS LPVApproaches in Germany," Aerospace Science and Technology, Vol. 47, Dec. 2015, pp. 280-290. https://doi.org/10.1016/j.ast.2015.09.035

[3] Perrin, O., Scaramuzza, M., Buchanan, T., and Brocard, D., "Flying EGNOS Approaches in the Swiss Alps," Journal of Navigation, Vol. 59, No. 2, 2006, pp. 177-185. https://doi.org/10.1017/S0373463306003754 
[4] Troller, M., Scaramuzza, M., Truffer, P., Wipf, H., and Raemi, S., "Performance Impact of Mountainous Topography for Cloud Break GNSS Procedure," Proceedings of the 25th International Technical Meeting of the Satellite Division of the Institute of Navigation (ION GNSS 2012), The Institute of Navigation, Manassas, VA, 2012, pp. $203-$ 209.

[5] “Aeronautical Information Publication," U.S. Terminal Procedures Publication, U.S. Dept. of Transportation. Federal Aviation Administration, April 2019.

[6] Aeronautical Information Publication Norway, effective date 28 March 2019, Avinor, 2019.

[7] "Aeronautical Information Publication France," French General Directorate of Civil Aviation, April 2019.

[8] "Aeronautical Information Publication Switzerland," Skyguide, April 2019.

[9] Performance-Based Navigation Manual, 4th ed., International Civil Aviation Organization Doc 9613, Montreal, 2012.

[10] Forssell, B., Radionavigation Systems. GNSS Technology and Applications Series, Artech House, Norwood, MA, 2008.

[11] EGNOS Safety of Life (SoL) Service Definition Document, European GNSS Agency, 3.2 ed., 2018.

[12] "Annex 6 to the Convention on International Civil Aviation: Operation of Aircraft, Pt. 1, International Commercial Air Transport-Aeroplanes, International Civil Aviation Organization, Montreal, 2016.

[13] "Procedures for Air Navigation Services-Aircraft Operations," Vol. 2, Construction of Visual and Instrument Flight Procedures (incorporating Amendment No. 7), 6th ed., International Civil Aviation Organization Doc 8168, Montreal, 2016.

[14] Annex 10 to the Convention on International Civil Aviation: Aeronautical Telecommunications Vol. 1, Radio Navigation Aids, 2006.

[15] "Minimum Operational Performance Standards for Global Positioning System/Wide Area Augmentation System Airborne Equipment," RTCA STD DO-229D, Washington, D.C., 2006.

[16] Jan, S. S., Chan, W., and Walter, T., "MATLAB Algorithm Availability Simulation Tool," GPS Solutions, Vol. 13, No. 4, 2009, pp. 327-332. https://doi.org/10.1007/s10291-009-0117-4

[17] NAVSTAR GPS Space Segment/Navigation User Interfaces, Unites States Air Force, IS-GPS-200 Revision J, 2018.

[18] Takasu, T., and Yasuda, A., "Development of the Low-Cost RTK-GPS Receiver with an Open Source Program Package RTKLIB," International Symposium on GPS/GNSS, 2009, pp. 4-6.
[19] Renfro, B. A., Stein, M., Boeker, N., Reed, E., and Villalba, E., "An Analysis of Global Positioning System (GPS) Standard Positioning Service (SPS) Performance for 2018," Space and Geophysics Lab., Applied Research Lab., Univ. of Texas at Austin TR-SGL-19-02, Austin, TX, 2019.

[20] Walter, T., Hansen, A., and Enge, P., "Validation of the WAAS MOPS Integrity Equation," Proceedings of the 55th Annual Meeting of The Institute of Navigation, The Institute of Navigation, Manassas, VA, June 1999, pp. 217-226.

[21] Christian, H., "Digital Terrain Models," Encyclopedia of Geodesy, Springer International, New York, 2014, pp. 1-6.

[22] SBAS FAS Data Block Tool, Ver. 3.1.0, Software Package, EUROCONTROL, Brussels, 2017, https://fasdb.eurocontrol.int/fasdb/app/about.htm [retrieved April 2017].

[23] APV SBAS Approach-Concept of Operations-Edition 1.0 EUROCONTROL, 2009

[24] Safety Case Guidance Material for Deployment of SBAS CAT I Edition 2.0 Accepta Project, 2017

[25] "Airworthiness Approval and Operational Criteria Related to Area Navigation for Global Navigation Satellite System Approach Operation to Localiser Performance with Vertical Guidance Minima Using Satellite Based Augmentation System. European Aviation Safety Agency AMC 20-28, 2012.

[26] Certification Specifications and Acceptable Means of Compliance for Airborne Communications, Navigation and Surveillance (CS-ACNS Issue 2), European Aviation Safety Agency EASA, 2019.

[27] Manual on Testing of Radio Navigation Aids Vol. 2-Testing of Satellite-Based Radio Navigation Systems, 5th ed., International Civil Aviation Organization Doc. 8071, Montreal, 2007.

[28] Quality Assurance Manual for Flight Procedure Design Volume 5-Validation of Instrument Flight Procedures, 1st ed., International Civil Aviation Organization Doc 9906, Montreal, 2012.

[29] Navigation System Database-ARINC 424-21, Aeronautical Radio, Inc., 2016.

[30] Falletti, E., Pini, M., and Presti, L. L., "Low Complexity Carrier-to-Noise Ratio Estimators for GNSS Digital Receivers," IEEE Transactions on Aerospace and Electronic Systems, Vol. 47, No. 1, 2009, 420-437.

H. Idris

Associate Editor 